\title{
A psychological and nutritional intervention program in individuals with disordered eating attitudes: a pilot study George Tsitsas* and Chrisanthy Blachaki
}

Address: Harokopio University, Athens, Greece

* Corresponding author

from International Society on Brain and Behaviour: 3rd International Congress on Brain and Behaviour

Thessaloniki, Greece. 28 November - 2 December 2007

Published: 17 April 2008

Annals of General Psychiatry 2008, 7(SuppI I):SII7 doi:I0.II86/I744-859X-7-SI-SII7

This abstract is available from: http://www.annals-general-psychiatry.com/content/7/SI/SI I7

(C) 2008 Tsitsas and Blachaki; licensee BioMed Central Ltd.

\section{Background}

Disordered eating attitudes and behaviours are common in young women in Western countries. Disordered eating attitudes are similar to eating disorders, but are less severe and do not meet the specific clinical definition for an eating disorder. The presence of these behaviors can lead to significant psychological and medical risks and are associated with the possibility of clinical eating disorders.

\section{Materials and methods}

The study involved 17 adult women, undergraduate students of the Nutrition and Dietetics Department between the ages of 18 and 20 years. Subjects were asked to complete the Eating Attitudes Test before and after the intervention. The EAT-26 (Garner, 1982) has been used as a measure of disordered eating and it is probably the most widely used standardized measure of symptoms and concerns characteristic of eating disorders. It contains 26 items and has found to identify eating disturbances in non-clinical samples. A score of $>20$ on the EAT-26 score represents disordered eating attitudes. A score of 20 or less is considered normal. Women received a psychological and a nutritional intervention, the duration of which was one hour per week for six consecutives months. The psychological intervention was designed to provide support for their self-esteem and their assertiveness especially in social situations. The nutritional intervention was designed to promote a more healthy diet. Women were assessed before the intervention and 6 months later (immediately post-intervention).

\section{Results}

The mean EAT-26 score before the intervention was $27.9 \pm 8.7(\min =21$ and $\max =46)$ and the mean EAT-26 score after the intervention was $22.3 \pm 6.3$ ( $\mathrm{min}=17$ and $\max =33$ ). A statistically significant difference was found in the eating attitudes $(\mathrm{p}=0.014)$ before and after the intervention (paired t-test).

\section{Conclusions}

According to the results of this study it can be suggested that the individuals supported in a nutritional and educational level are likely to adopt better eating attitudes and some of them can stop suffering from disordered eating attitudes.

\section{References}

I. Polivy J, Herman CP: Dieting and bingeing: a causal analysis. Am Psychol 1985, 40: 193-20I.

2. Levine M, Smolak L: Toward a model of the developmental psychopathology of eating disorders: the example of early adolescence. In The etiology of bulimia nervosa: the individual and familial context Edited by: Crowther JH, Tennenbaum DL, Hobfoll SE, Stevens MAP. Washington: Hemisphere; 1992:59-80.

3. Fisher M, Schneider M, Pegler C, Napolitano B: Eating attitudes, health risk behavior, self-esteem and anxiety among adolescent females in a suburban high school. J Adolesc Health 1991, 1 2:377-84.

4. Ressler A: “A body to die for": eating disorders and bodyimage distortion in women. Int J Fertil Womens Med 1998, 43:133-138. 